\title{
SEMANTIC AND SYNTACTIC INTEROPERABILITY OF BIM AND ASSET MANAGEMENT DATA
}

\author{
Karim Farghaly, Henry F. Abanda, Christos Vidalakis, and Graham Wood \\ Oxford Brookes University, Oxford, United Kingdom
}

\begin{abstract}
Over the recent years, there has been a growing interest in how Building Information Modelling (BIM) can facilitate effective Asset Management (AM). BIM$\mathrm{AM}$ data integration has come with issues related to establishing an effective process to extract, store, and distribute data to ensure interoperability. Several information exchange specifications such as COBie and SPARKie have been developed to enable effective interoperability for better building assets operation and maintenance. Due to asset heterogeneity, the exchange models cannot be generalized and applied to all assets systems. Exchange models need to be developed for particular asset systems based on their functionality and building type. In order to contribute to overcoming the BIM-AM interoperability challenge, this study aims to provide the required semantic and syntactic interoperability aspects for the data exchange of assets that consume energy from the BIM systems to the AM systems during the handover stage.
\end{abstract}

\section{Introduction}

Asset management is a term that measures the capacity and ability of an asset to achieve its objectives (Riso, 2012). An asset could be an item, equipment, space, or any other entity that generates either financial or nonfinancial value for the organization. Appropriate and reliable asset information, such as asset location, specifications, warranties and maintenance schedules are essential for supporting effective decision-making during asset operation lifecycles (Love et al, 2015). Due to the inadequate interoperability among the information systems utilized in the different stages of the building, excessive time and costs are spent to locate and verify the required information from previous activities for operating and maintaining the building assets (Teicholz, 2013).

Accordingly, AM requires an information system that automatically captures, stores, and integrates the data required to support better decision-making across the diverse array of requirements. An ideal information system that can store and provide the asset data during all phases of the building and can record the changes in conditions of the maintained and operated set of assets is required (Amadi-Echendu et al, 2010; Teicholz, 2013). Building Information Modelling (BIM) has been argued to provide the required information system for solving AM challenges. Despite BIM capabilities and the promises for improving AM practices, the implementation of BIM in Facilities Management (FM) is generally, and in AM particularly, filled with obstacles (Eadie et al, 2015; Ibrahim et al, 2016). It has been argued that the interoperability challenge is the first key barrier to overcome, as the entire theoretical framework of BIM data being used for FM is predicated on the assumption that data can be exchanged between software programs (Kensek, 2015).

Most of available works concentrated on developing technology driven functions and applications to overcome the syntactic interoperability barrier rather than developing computable information requirements for better semantic interoperability (Cavka et al, 2017). The available syntactic interoperability approaches include using Industry Foundation Classes (IFC) or Construction Operation Building Information Exchange (COBie), and/or proprietary middleware (such as: Ecodomus). Even with these approaches, syntactic interoperability solutions alone cannot ensure that the integration of BIM-AM could achieve the required expected benefits and results. Pärn et al.(2017) critiqued that semantic interoperability is the single most important interoperability challenge to overcome when integrating BIM data with other systems such as AM platforms.

In spite of all of the available studies and the integration promises, there are still gaps to be filled and challenges to be solved between the integration potential and its realization in the asset management fields. Accordingly, this research aims to contribute in filling the interoperability gap by providing the required semantic and syntactic interoperability aspects for the data exchange of assets that consume energy from the BIM systems to the AM systems during the handover stage.

\section{Research Methodology}

Due to the heterogeneity of assets, the required information cannot be generalized for all assets (Cavka et al, 2017). However, the required information taxonomy can be developed for assets based on their functionality in certain building types (Farghaly et al, 2018). On the other hand, the need of providing sustainable performance during the building lifecycle has been emphasized. This study focuses on assets that consume energy. Cavka et al. (2017) stated that developing a conceptual framework which identifies the owner requirements and links them with the digital and physical products can improve the AM performance and sustainability in particular. 


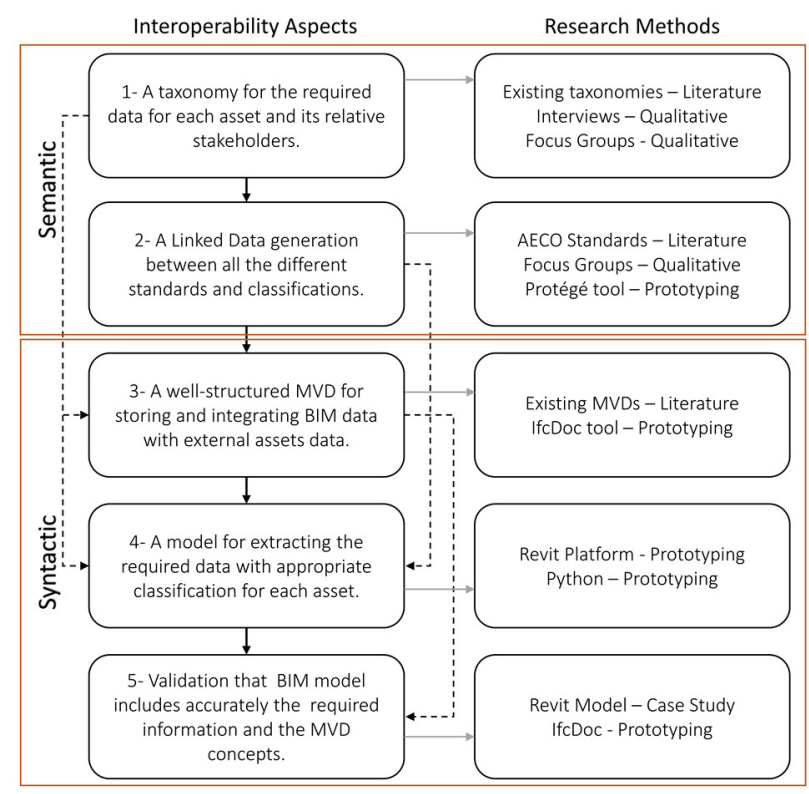

Figure 1: Research method framework

The considerations and recommendations above provide the foundation for the development of a new Asset Consuming Energy Information Exchange (ACEie) framework (). The framework can still be updated and adapted to cover all of the operable building assets.

The first two steps aim to identify the client requirements and related concepts to the required information in order to fulfill the semantic interoperability aspect. Therefore, qualitative data collection methods such as semi-structure interviews and focus groups would serve as appropriate tools for achieving these aims (Saunders et al, 2011). Five semistructured interviews and two focus groups with eight experts have been conducted during the first two steps. Semi-structured interviews were conducted with two facility managers, an asset data manager, and two information managers who were involved in the decision to adopt BIM for FM in their companies. The selection criteria of the interviews includes BIM and AM experts in world-class BIM projects and construction organizations, which incorporates BIMcompliance projects throughout the UK. The focus group was conducted with eight experts in the construction and/or operation industry. The proficiency for eligibility to participate in the focus group was determined based on different criteria namely; five years' experience in BIM and/or asset management and mechanical or electrical engineer. The focus group started with high level of involvement of the interviewer, by giving an introduction to the different classifications for the building assets and brief introduction to taxonomy, LD and ontologies. The first question is then enquired, leading to an unstructured discussion about the potential answers. During discussion, the interviewer level of involvement was low, then moved to high by concluding the discussion and then moving to the next question. Another focus group was conducted with the same participants. The second focus group has been led to evaluate and validate the developed taxonomy and the mapping developed between all the different ontologies for each individual asset that consumes energy during the development of ontologies stage. The interviewer showed the developed mapping between the different standards for each asset and consequently the participants interact to agree/disagree/refine the developed mapping and the attributes properties. The focus group's discussion was whether the abstracted concepts were precise and accurate or not.

\section{ACEie required taxonomy}

The paradigm methodology leads to taxonomies with two-way hierarchical relationships between classes and the faceted analysis leads to taxonomies, whose subject matters are classified using multiple perspectives (facets). The characteristics of the tree structure approach are the most suitable for developing the required taxonomy. After the interviews, the preliminary taxonomy based on the literature was modified and updated. Figure 2 is a diagrammatic representation of the proposed taxonomy of the required data for successful implementation of BIM in AM. The taxonomy adopts a two-level tree structure with a top-down development process. The top level is classified into six main branches/classes namely location/space, classifications, specifications, warranty, assets capex, and maintenance. At the second level, sixty subclasses are representing the required BIM data/parameters for AM at the handover stage (Farghaly et al, 2018). 


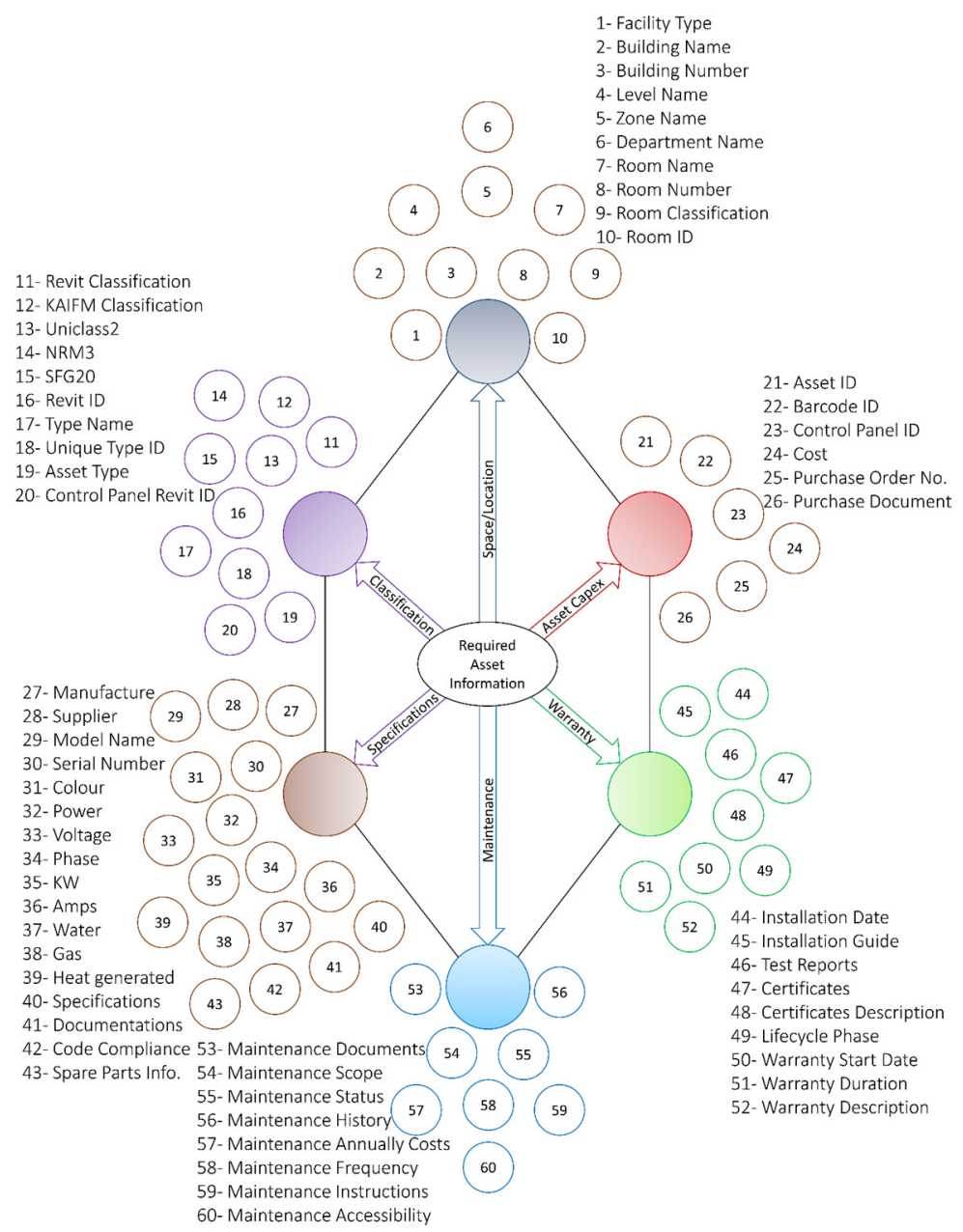

Figure 2: Taxonomy for the required information for assets consuming energy (Farghaly et al, 2018).

\section{ACEie standards ontology}

Providing object-oriented cross-domain linking with the required information can provide more efficient and adequate solutions to achieve semantic interoperability between BIM and AM (Kim et al, 2018) as well as the implementation of syntactic interoperability solutions such as Model View Definitions (MVD).The information related to the design and construction stages are managed by several identified standards/vocabularies in the building information models. However, they cannot manage the asset operation and maintenance activities due to the different scopes (Kim et al, 2018).

Different ontological sources/vocabularies from the Architecture, Engineering, Construction and Operation (AECO) domain are selected in the research to achieve the required cross-domain linking, such as NRM (New Rules Measurement) 1, NRM 3, Uniclass2, SFG20, IFC, and finally Revit as a BIM Platform. NRM is a suite of documents issued by the Royal Institution of Chartered Surveyors (RICS) quantity surveying and construction professional group. NRM1 (NRM Order of cost estimating and elemental cost planning) has been published to provide a standard and guideline on the quantification of building works for cost estimate purposes based on the UK practice, while NRM3 (Order of cost estimating and cost planning for building maintenance works) has been written to provide a standard and guideline for the quantification and description of the maintenance works for cost estimate purposes during all phases of the building. SFG20 provides the benchmark for optimum maintenance, avoiding over or under maintaining of assets and the backbone to building engineering services maintenance industry (This is an online web-based specification, available at http://www.sfg20.com [last viewed 03 April 2019]). SFG20 is a web-based online application where the different tasks of maintenance can be assigned to project assets. The SFG20 core library offers users more than 400 industry-standard maintenance specifications covering all principal types of heating, cooling and ventilation, installation, plant and electrical services, complete with regular technical updates. Although SFG20 is not specified in PAS 1192 , it can be easily determined as it is aligned with NRM3. The authors accessed the SFG20 through a free trial request where the standard is provided in an online tree taxonomy. 


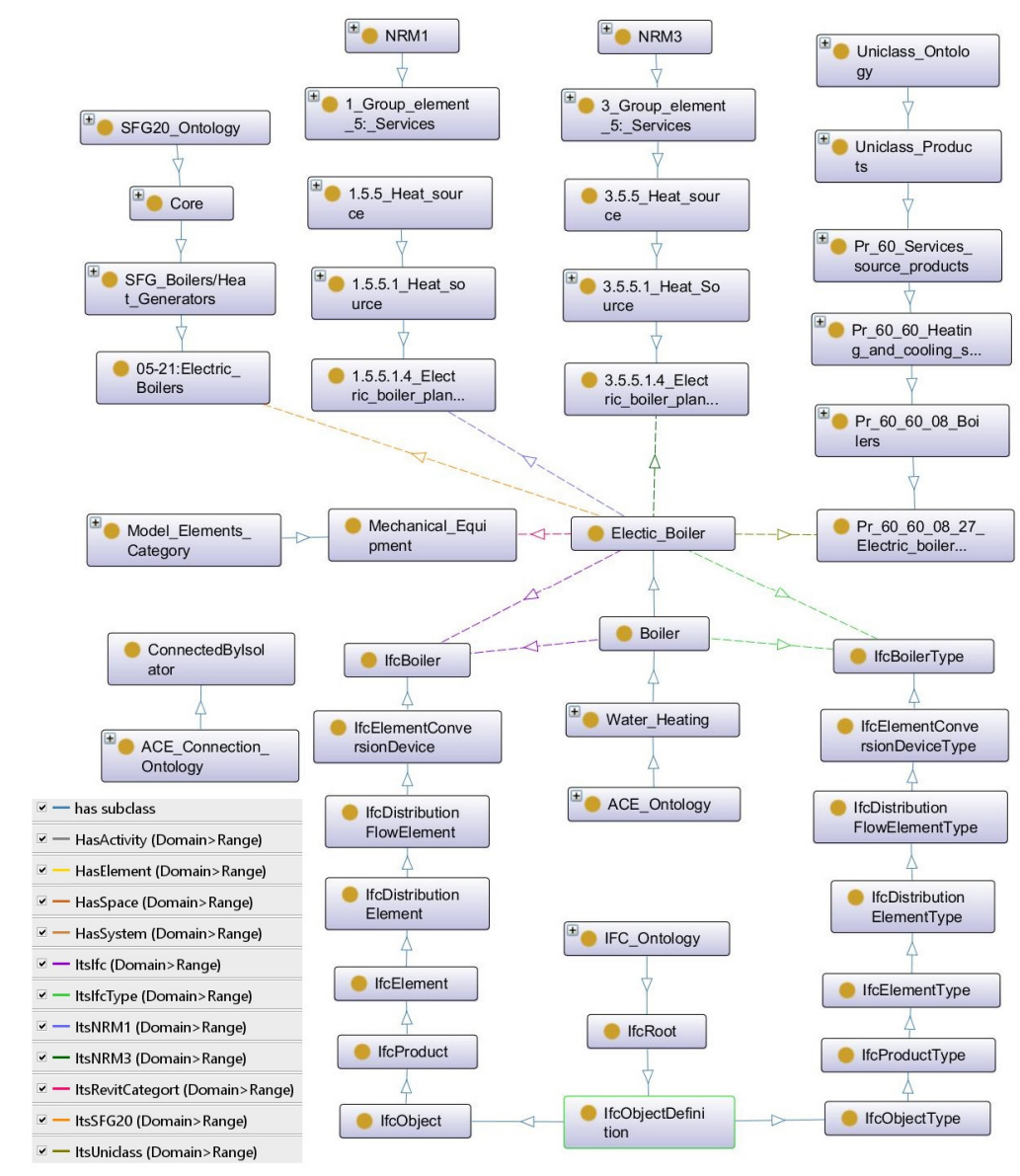

Figure 3: An example of the linking between the different AECO vocabularies for building assets.

Once the ontological sources are selected and accessed, focus group is conducted aiming to make visible indicators that have not been previously harvested by the ontological sources and to identify relationships between concepts, such as the interconnections, incoming, and outgoing links between vocabularies/classifications. In the end of the first focus group, the links between the classes of the different classifications were documented. Figure 3 illustrates the link and mapping between the different ontological sources for a specific asset (Boiler). The hierarchical sequence for each standard is represented to reach the class to symbolize an electric boiler. The different relationships are color-coded and depicted in the bottom left of Figure 3.

Once cross-domain mapping is achieved, syntactic and semantic correctness of the developed ontologies and also the mapping between the different ontologies have to be verified. A logical based approach is adapted for syntactic evaluation. The HermiT reasoner was used to validate the consistency with the ontologies used and several other SPARQL queries are executed to observe the credibility of the obtained results. While a feature-based approach is adapted for the semantic evaluation of the developed ontologies. The feature-based approach evaluates the ontologies' quality by engaging users and expertise.

\section{ACEie MVD}

Once the semantic interoperability aspects are covered, it is time to start the development of the MVD. This step aims to develop an MVD that meets the end-user's needs in an implementable format for sending and receiving software applications. For generating an MVD, four different approaches can be adapted; mvdXML, Generalized Model Subset Definition (GMSD), eXtended Process to Product Modelling (xPPM), and Semantic Exchange Module (SEM). Based on the comparative study by Zhang et al. (2015), it emerged that the mvdXML is the most appropriate approach on developing the proposed MVD. The mvdXML is an open standard developed by buildingSMART to define model subsets and validation rule sets. The IFC Documentation Generator (IfcDoc) is a free tool issued by buildingSMART based on MVDXML. IfcDoc reads and writes mvdXML files and also provides a graphical user interface for defining all of the different content within an mvdXML file, such as concepts, concept templates, and model views. This tool autogenerates MVD diagrams, output HTML documentation for model views, and MVD documentation. 
The first step to developing an MVD, using the IfcDoc tool, is to define a new MVD in the baseline file of the selected IFC release in the overview description (IFC4 ADD2). The IFC4 Add2 is published on 15th July 2016 as a buildingSMART final standard (www.buildingsmart-tech.org/ifc/IFC4/Add2/html/).

The baseline IFC file contains the full IFC schema and a set of reusable MVD concept templates and concept use definitions. A new MVD, called ACEie, is added under the scope. An MVD is assembled using exchange models, entities, concepts, property sets, and properties/attributes (Figure 4).

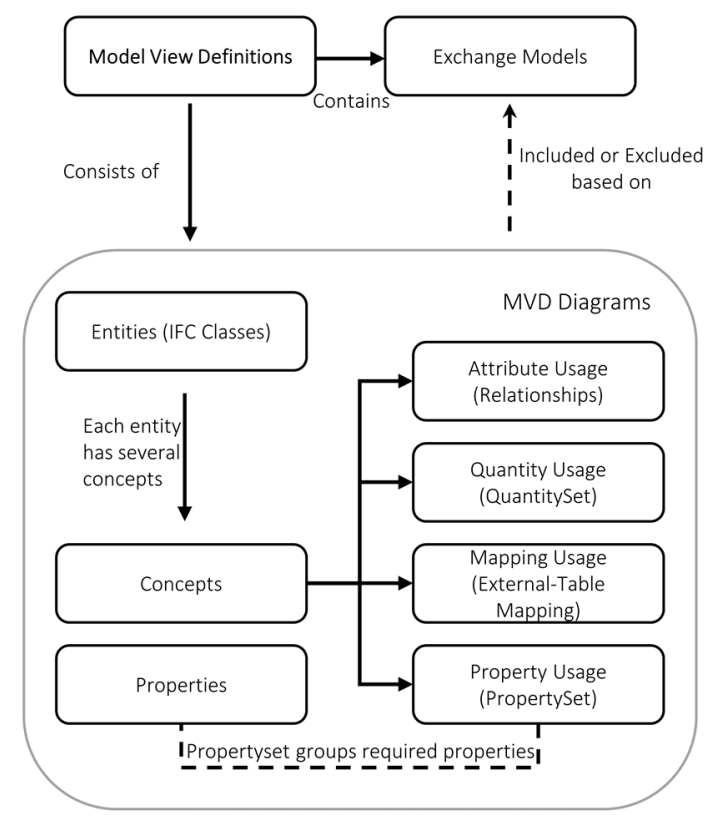

Figure 4: The main components of MVD

Exchange models/definitions (EMs) indicate a particular subset of information to be exchanged in a particular stage of the building lifecycle. For example, COBie V2.4 consists of 28 EMs and their related exchange requirements. ACEie MVD consists of only four EMs as it only serves the handover stage of existing buildings and their new extensions as predefined in the developed IDM. The four EMs are ACEie_Space/Location, ACEie_Classification, ACEie_Capex\&Warranty, and ACEie_Maintenace.

More than 800 entities are included in the IFC4 ADDD2 schema. The most abstract and root class for all IFC entities is the IfcRoot. All entities that are subtypes of IfcRoot can be used independently and they are divided into three main subtypes, which form the first level of specialization within the IFC class hierarchy, namely IfcObjectDefinition, IfcPropertyDefinition, and IfcRelationship. The required classes are selected and added to the ACEie exchange model. Although the IFC4 schema has enriched the level of detail of several assets, such as boilers, it still lacks additional classifications for some assets instead of using generic classes (Pinheiro et al,
2018). To overcome this limitation, both air-handling units and fan-cooling units were mapped to IfcAirToAirHeatRecovery and also all of the kitchen assets were mapped to IfcElectricAppliance. Once every entity is identified and added to the model view, the required information from each asset will be established using the IFC concepts.

Concepts represent a use definition for a particular entity with specific rules to be enforced (Chipman et al, 2014). The concepts generally encompass a series of specifications and implementation agreements of IFC data exchanges required for one or more entities, their relationships, and their attributes (Lee et al, 2018). The hierarchy of the building spatial elements required in the EM1 (ACEie_Space/Location EM) is defined using the predefined "Object composition" concept template. The subtype "IfcRelAggregates" is utilized to form the hierarchical structure between the different instances. Another predefined concept template is used to link between the instance and its relevant type using the subtype "IfcRefDefinesByType".IfcRelDefinesByProperties is used to add all the required property sets. Property Sets Definitions (PSD) is explicitly explained as it is used in the development of the proposed MVD.

PSD schema is an XML schema, defined as IfcPropertySet to determine all properties and property sets both inside and outside the IFC specifications. Each property set holds the required non-geometric information for specific applications. BuildingSMART developed the PSD schema to provide capabilities for the stakeholders to add the required information to achieve their purposes. Six property sets have been added to the IfcElectricDomain property sets to represent the required information for the ACEie exchange. The six property sets and their properties are based on the developed taxonomy. Overall, 60 parameters are defined and assigned to the selected objects for the exchange and the type of IfcValue has been selected for each of them separately, based on the attribute measurement. For instance, IfcElecticCurrentMeasure is selected as the primary data type for the "current" attribute, while IfcLabel is selected for all the different location attributes. In addition to the property sets, quantity sets were defined to provide the essential information related to measured attributes, such as asset dimensions.

\section{ACEie Revit Plug-in}

After the development of the MVD, it is time for implementing the solution in the software environment and apply it toward different project. The selected platform should have a dedicated building modeling section (Mechanical and Electrical section), supports object extraction, and accommodates interaction with external plug-in object-oriented interfaces. The Revit platform was found to be suitable with rich SDK 
documentations and also available to researchers at the subscribing institutions.

In this research, the process of adding, connecting, and extracting the required information from the building information models for the proposed exchange is translated by the developed Revit plug-in. Revit 2019 was selected as it is the latest version released at the time of the research and it also contains several enhancements in the IFC export functions. The developed Revit plug-in consists of three primary addins. The first add-in implements the required information - non-graphical information - that is not predefined in the Revit elements. The second add-in function is to fill in some of the information automatically and it consists of three main functions (Figure 5).

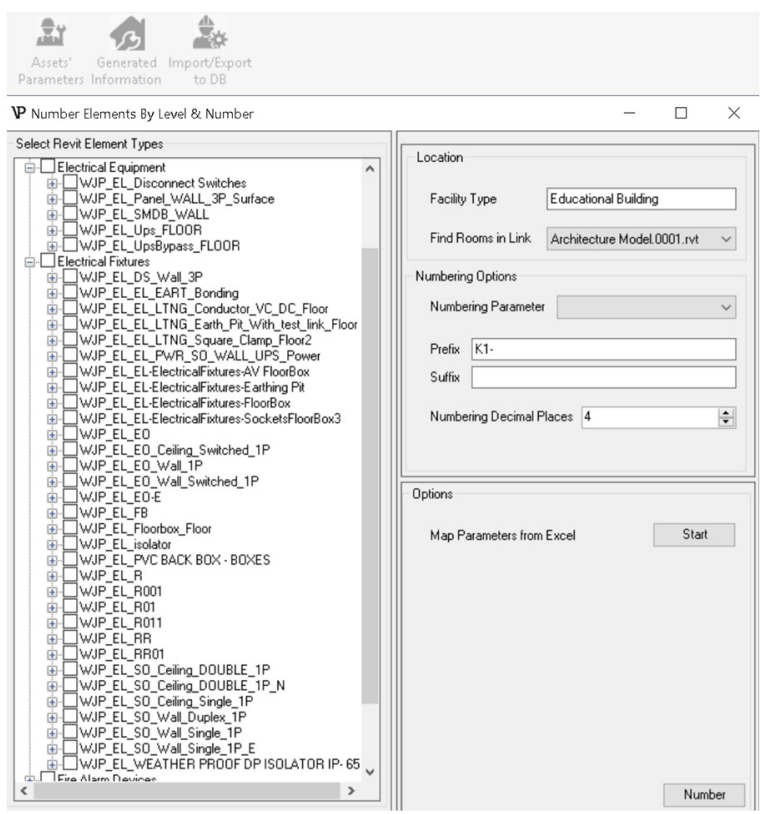

Figure 5: Screenshot of the developed Revit plug-in

The first function reads from the linked architecture model, recognizes the room space hosts the asset, and finally fills in all the parameters related to location and spaces as defined in the architecture rooms. The second function numbers the assets of the same type in the same room to easily identify them. The third and last function of the second add-in is filling the classification parameters based on the developed cross-domain linking ontologies. The third and last add-in is developed to ensure the exportation of the properties in the correct property sets as defined in the MVD. In Revit 2019, an advanced IFC export settings tab is added and one of the added functions is the export of property sets. Several options for property sets exportation, such as export IFC common property sets, export base quantities, and export schedules as property sets. During the focus group, it has been noticed that the BIM engineers are not very familiar with IFC property sets and they would prefer generating all of the requirements in the Revit environment. Therefore, the selected approach for exportation is using the schedules in Revit as property sets. The third add-in automatically generates six schedules named as the property sets defined in the MVD stage with the parameters hosted in each property set.

\section{ACEie Evaluation}

The completion of the study requires validation that the BIM model accurately includes the information defined in the data exchange requirements and the MVD. Several checking routines, named validation rules, are performed at this stage to guarantee that the BIM models are generated and operated correctly. In project validation, data validation tools compare between two files; the IFC file of the project (Design Data) and the reference MVD (Constrain Data) (See et al, 2012). The selected project is an extension for an educational institute (Figure 6). The architecture model includes all the different required spaces and spatial requirements such as classrooms, toilets, corridors, and the locker room. The mechanical and electrical model include all the different assets that consume energy and other assets such as sockets, switches, ducts, and mechanical equipment.

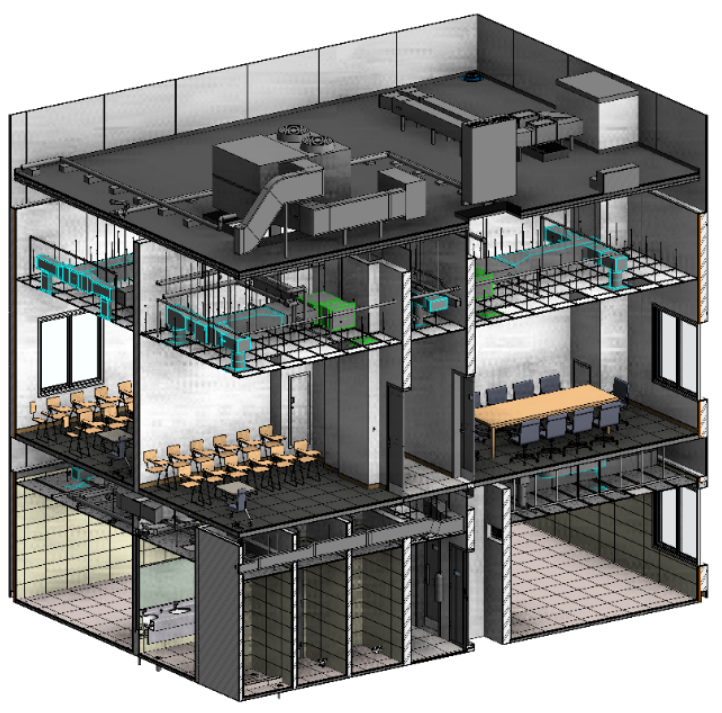

Figure 6: BIM model of the extension of the educational institute.

Each rule type was coded and identified in the ACE MVD and added through the IfcDoc tool. The logical expressions in IfcDoc, which includes several composition order of rules were used to develop the five required rule types of the developed MVD. The rule types and logic are:

- Verification of the presence of an attribute.

- Verification of the presence of an element.

- Verification of data accuracy. 
- Verification of the cardinality of an element.

- Verification of the presence of property set and its required properties.

The IfcDoc tool validates the selected IFC model against the model view based on the coded and assigned rule types to the pertinent concepts. It provides two output formats for the validation results: the interactive user interface color-coded validation report and the HTML format. The color-coding differentiates the validation outcomes: Pass, Fail, No Instance, and Not Applicable. Entities and attributes that satisfy the concept rules are represented in green, while the invalid ones are represented in red. Moreover, the entities that do not have relations or attributes are not colored.

\section{Conclusions}

In spite of the BIM competencies which can facilitate managing and operating building assets effectively, the implementation of BIM in AM still faces several obstacles. One of the main obstacles is achieving interoperability between BIM and AM platforms. Several information exchange specifications such as COBie and SPARKie have been developed to achieve interoperability. However, it has been argued that these information exchange specifications alone are not sufficient as they are generalized for all assets or for specific asset system. This research proposed five aspects to enhance the interoperability between BIM and AM platforms armed with an example for assets that consume energy.

This research contributes to knowledge in two different contexts, which are theoretical and practical. Within the theoretical context, there were two main research outcomes which are related to semantic interoperability. The first outcome/finding was a conceptual taxonomy where the critical information required from BIM models for asset management practice are identified, and workflows and roles and responsibilities to fully integrate these data sets are stated. Moreover, the conceptual taxonomy is polished in the light of the case study evaluation. The second outcome was a linked data where all the different standards and classifications used in the AEC and O\&M domains are linked to each other's as ontological sources to enhance the semantic interoperability among BIM and AM systems. The developed process map for the Linked Data development also contributes to the knowledge of managing and operating building assets without the authorization of BIM platforms and with exploiting Linked Data technologies.

On the other hand, within the practical context, an innovative model view definition (MVD) that would improve the integration between BIM data and other asset databases for better asset management decisions was developed. The developed MVD specifies the appropriate entities required from the IFC schema to maintain and operate the assets in a building which consumes energy. Also, a possible application in a BIM platform to identify and extract the required data based on the proposed taxonomy was developed and demonstrated in a real-world project. The process of adding, connecting, and extracting the required information from the building information models for the proposed exchange is translated by the developed Revit plug-in. The proposed approach to enhance the interoperability challenge between BIM and AM platforms can be adapted for all assets not only the assets that consume energy. Future work includes more case studies of different building types for evaluation of the proposed framework and developed taxonomy, ontologies, and MVD.

\section{References}

Amadi-Echendu, J. E., Willett, R., Brown, K., Hope, T., Lee, J., Mathew, J., Vyas, N. \& Yang, B.-S. (2010) What is engineering asset management?, Definitions, concepts and scope of engineering asset managementSpringer, 3-16.

Cavka, H. B., Staub-French, S. \& Poirier, E. A. (2017) Developing owner information requirements for BIM-enabled project delivery and asset management. Automation in Construction, 83, 169-183.

Chipman, T., Liebich, T. \& Weise, M. (2014) Specification of a standardized format to define and exchange Model View Definitions with Exchange Requirements and Validation Rules. BuildingSmart.

Eadie, R., Browne, M., Odeyinka, H., McKeown, C. $\&$ McNiff, S. (2015) A survey of current status of and perceived changes required for BIM adoption in the UK. Built Environment Project and Asset Management, 5(1), 4-21.

Farghaly, K., Abanda, F. H., Vidalakis, C. \& Wood, G. (2018) Taxonomy for BIM and Asset Management Semantic Interoperability. Journal of Management in Engineering, 34(4), 04018012.

Ibrahim, K. F., Abanda, F. H., Vidalakis, C. \& Woods, G. (2016) BIM for FM: Input versus Output data, Proc. of the 33rd CIB W78 Conference 2016. Brisbane, Australia.

Kensek, K. (2015) BIM Guidelines Inform Facilities Management Databases: A Case Study over Time. Buildings, 5(3), 899-916.

Kim, K., Kim, H., Kim, W., Kim, C., Kim, J. \& Yu, J. 
(2018) Integration of ifc objects and facility management work information using Semantic Web. Automation in Construction, 87, 173-187.

Lee, Y.-C., Eastman, C. M. \& Solihin, W. J. A. i. C. (2018) Logic for ensuring the data exchange integrity of building information models, 85, 249262.

Love, P. E., Matthews, J. \& Lockley, S. (2015) BIM for built asset management. Built Environment Project and Asset Management, 5(3).

Pinheiro, S., Wimmer, R., O’Donnell, J., Muhic, S., Bazjanac, V., Maile, T., Frisch, J. \& van Treeck, C. (2018) MVD based information exchange between BIM and building energy performance simulation. Automation in Construction, 90, 91-103.

Pärn, E., Edwards, D. \& Sing, M. (2017) The building information modelling trajectory in facilities management: A review. Automation in Construction, 75, 45-55.

Riso, I. (2012) DIS 55000: Asset managementOverview, principles and terminology. ISO.

Saunders, M., Lewis, P. \& Thornhill, A. (2011) Research methods for business students, 5/e. England: Pearson Education India.

See, R., Karlshoej, J. \& Daves, D. (2012) An Integrated Process for Delivering IFC Based Data Exchange.

Teicholz, P. (2013) BIM for facility managersJohn Wiley \& Sons.

Zhang, C., Beetz, J. \& Weise, M. (2015) Interoperable validation for IFC building models using open standards. Journal of Information Technology in Construction (ITcon), 20(2), 24-39. 